\title{
SCOLIOSIS AFTER THORACOPLASTY
}

\author{
R. D. Loynes, ${ }^{*}$ Liver Pool, England \\ From the Department of Orthopaedic Surgery, University of Liverpool
}

\begin{abstract}
Although thoracoplasty is now seldom performed, an analysis of the effects of this procedure upon the spine affords an opportunity to study the role of the ribs in spinal stability.

In 1934 Bisgard reported that thoracoplasty could produce scoliosis in man, and in 1935 he reported the results of experiments in animals. In these he performed costectomy and a variety of other operative procedures and showed that the removal of ribs in animals, as in humans, produced scoliosis; he also noted that the rib remnants regenerated and fused to form a solid plaque of bone. More recently, several authors have reported the results of other animal experiments. Langenskiöld and Michelsson (1961, 1962) and Michelsson (1965) described the results of removal of the posterior ends of ribs, tethering of one side of the spine with sutures, and division of the costo-transverse ligaments. Manning (1968) reported that removal of the posterior ends of ribs produced scoliosis but that division of the costo-transverse ligaments failed to do so. Langenskiöld and Michelsson (1962) found, in contrast, that division of these ligaments did produce scoliosis. Thus the results of animal experiments have sometimes been conflicting. It should be noted that the animals used were often immature and that the progression of the spinal curve is influenced by epiphysial growth, whether this be to favour the development of scoliosis, as suggested by Hueter and Volkmann (1869), or to oppose it, as suggested by Langenskiöld (1968).

Little has been written about the effects of costectomy upon the human spine. Stauffer and Mankin (1966) suggested that the degree of curvature was closely related to the number of ribs removed, and found that the removal of transverse processes increased the curvature. They suggested that one possible explanation for the phenomenon of scoliosis after thoracoplasty was imbalance of the pneumatic support of the spine by the lungs. This paper reviews the effects of thoracoplasty upon the development of scoliosis in adults. The findings show certain important differences from those of Stauffer and Mankin.
\end{abstract}

\section{MATERIAL}

The cases reviewed are of 243 thoracoplasty operations performed from 1945 to 1955 in 241 patients as part of their treatment for pulmonary tuberculosis. They were collected from three chest hospitals in the Merseyside and North Wales area. The cases were intentionally taken from different sources and from operations performed over a period of time, so that the effects of various procedures upon the development of scoliosis could be assessed. In 239 patients unilateral thoracoplasty was performed, usually in more than one stage. In one case a second thoracoplasty was performed on the same side two years after the first. In another case a seven-rib thoracoplasty was performed on the left side and seven months later a four-rib excision on the right.

The cases were analysed in order to decide the relative importance of the following factors: 1) the action of the erector spinae muscles; 2) pressure of the ribs; 3) pneumatic support of the lungs; 4) ligamentous support; and 5) fusion between ribs.

\section{THE OPERATION}

The operations performed were all variations of thoracoplasty and included removal of different numbers of ribs from the tubercle laterally, with these additional procedures in certain

\footnotetext{
* Formerly Research Fellow.
} 
cases: 1) removal of the transverse process along with the head, neck and tubercle of the rib, as well as the rib lateral to the tubercle; 2 ) embedding of the scapula so that the inferior angle and a varying part of the blade were sited inside the thoracic cage; subsequently the vertebroscapular muscles were sutured to maintain this new position; 3) apicolysis; 4) "Semb space" air refills, performed on some occasions after apicolysis; and 5) lobectomy or pneumonectomy.

\section{METHOD}

Only the case notes and radiographs were reviewed; the patients themselves were neither examined nor interviewed. The following observations were made in each case: 1) the age at the time of thoracoplasty; 2) the side, site and type of thoracoplasty; 3 ) any curvature before operation; 4) the angles of curvature approximately one week and six months after operation, and in some cases the angle several years later; 5 ) the level of the apex and the number of vertebrae involved in the curve; and 6) the amount of rotation of the apical vertebra.

The angles of the curve were measured by the method of Cobb (1948) and the degree of rotation by the method of Nash and Moe (1969). The degree of rotation was designated as $0,1,2,3$ or 4 according to the amount of displacement of the convex side pedicle across the vertebral body, as shown in Figure 1. If

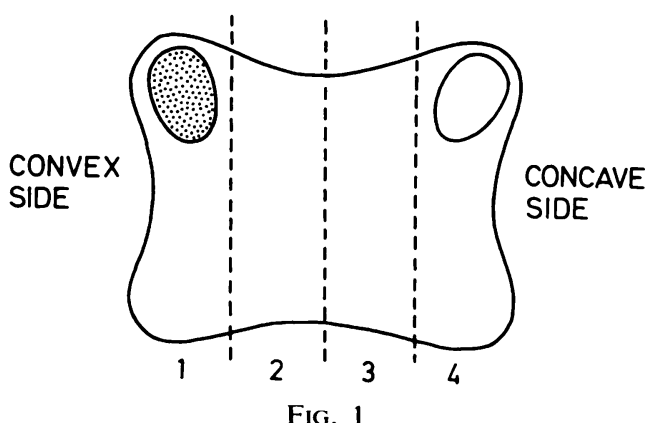

The degrees of vertebral rotation. As the image of the pedicle on the convex side moves across the vertebra, 1, 2, 3 and 4 degrees of rotation are recorded when the pedicle lies within the appropriate vertical quarter of the body as shown. the pedicles were symmetrical and showed no distortion this was recorded as 0 . If the pedicles were asymmetrical or showed distortion and the pedicle on the convex side remained within the first segment, this was recorded as 1 , and so on.

\section{RESULTS}

The results are shown in tabulated and graphic forms. The "angle of curve" quoted represents the difference between the pre-operative radiographs and those taken on average six months later. The results are discussed as follows: 1) the influence of the type of operation and the number of ribs removed;2) the influence of the age of the patient; 3) the progression of the curve; 4) rotation of vertebrae; and 5) the level of the apex.

Type of operation and number of ribs removed-Table I shows the number of patients subjected to each of the six types of operation, and Tables II to VIII show the angles of the curves related to the number of ribs removed. With this number of results, a statistical analysis seems both appropriate and desirable. Such an analysis is more likely to be of value if there is a normal pattern of distribution of the results (Bishop 1969). That this is the case can be seen in Figure 2. Figure 3 shows the relationship between the mean values of the angles observed for each number of ribs removed. This relationship is expressed as the calculated regression line of the $\mathrm{Y}$-axis (the angle of curve) on the $\mathrm{X}$-axis (the number of ribs removed). Also shown are the standard deviations of the means, the standard deviations of the samples and the range of values found in each sample. The correlation is significant at the 1 per cent level of probability. Despite this close correlation, it can be seen that the range of observed angles is quite wide. Take, for example, the two extremes of angle produced by ten-rib thoracoplasty. Figure 4 shows a case in which the result was a scoliosis of 9 degrees and Figure 5 shows one of 80 degrees.

It appears, therefore, that some factor other than the number of ribs removed may be concerned in determining the degree of curve produced. Consequently the results have been 
TABLE I

To Show the Number of Each Type of Operation in a Total of 243 Cases

\begin{tabular}{|c|c|c|c|c|c|c|c|c|}
\hline Number of ribs removed & 3 & 4 & 5 & 6 & 7 & 8 & 9 & 10 \\
\hline Total number of cases & 6 & 12 & 47 & 20 & 79 & 36 & 17 & 14 \\
\hline Transverse processes removed & - & - & - & - & 3 & 1 & 2 & 1 \\
\hline Apicolysis, scapula not embedded & 4 & 9 & 33 & - & 25 & 6 & 1 & 2 \\
\hline Apicolysis, scapula embedded. & - & - & - & 2 & 6 & 2 & 1 & - \\
\hline No apicolysis, scapula not embedded & 2 & 3 & 12 & 4 & 16 & 9 & 8 & 5 \\
\hline No apicolysis, scapula embedded & - & - & 2 & 14 & 29 & 18 & 5 & 6 \\
\hline
\end{tabular}

There were eleven cases of thoracoplasty with lobectomy or pneumonectomy.

TABLE II

The Results in all 243 Cases Regardless of THE PROCEDURe

\begin{tabular}{|c|c|c|}
\hline $\begin{array}{l}\text { Number } \\
\text { of ribs }\end{array}$ & $\begin{array}{c}\text { Angle of curvature } \\
\text { (degrees) }\end{array}$ & Average \\
\hline 3 & $6: 10: 11: 12: 17: 20$ & 13 \\
\hline 4 & From 0: 4 to $29: 29$ (13 cases) & 13 \\
\hline 5 & From 3: 6 to $26: 27$ ( 50 cases) & 14 \\
\hline 6 & From 6: 7 to $26: 27$ ( 22 cases) & 16 \\
\hline 7 & From 0: 4 to $53: 61$ (84 cases) & 18 \\
\hline 8 & From $4: 4$ to $31: 46$ (37 cases) & 18 \\
\hline 9 & From 9: 10 to $27: 47$ (17 cases) & 18 \\
\hline 10 & From 9: 9 to $40: 80$ (14 cases) & 25 \\
\hline
\end{tabular}

TABLE III

The Results in Seven Cases of Thoracoplasty with Removal of Transverse Processes

\begin{tabular}{|c|c|c|}
\hline $\begin{array}{c}\text { Number } \\
\text { of ribs }\end{array}$ & $\begin{array}{c}\text { Angle of curvature } \\
\text { (degrees) }\end{array}$ & Average \\
\hline 7 & $10: 26: 35$ & 24 \\
\hline 8 & 46 & 46 \\
\hline 9 & $14: 47$ & $30 \cdot 5$ \\
\hline 10 & 80 & 80 \\
\hline
\end{tabular}

TABLE IV

The_Results in Eighty Cases of Thoracoplasty WITH APICOLYSIS BUT THE SCAPULA NOT EMBEDDED

\begin{tabular}{|c|l|c|}
\hline $\begin{array}{c}\text { Number } \\
\text { of ribs }\end{array}$ & \multicolumn{1}{|c|}{$\begin{array}{c}\text { Angle of curvature } \\
\text { (degrees) }\end{array}$} & Average \\
\hline 3 & $10: 12: 17: 20$ & 15 \\
4 & From 7:9 to $22: 29$ (9 cases) & 14 \\
5 & From 6: 7 to 26:27 (33 cases) & 15 \\
6 & No cases & - \\
7 & From 4:8 to $46: 53(25$ cases) & 21 \\
8 & $15: 15: 17: 19: 22: 24$ & 19 \\
9 & 20 & 20 \\
10 & $19: 24$ & $21 \cdot 5$ \\
\hline
\end{tabular}

TABLE V

The Results in Eleven Cases of Thoracoplasty WITH APICOlysis AND WITH THE SCAPUla EMBEDDED

\begin{tabular}{|c|l|c|}
\hline $\begin{array}{c}\text { Number } \\
\text { of ribs }\end{array}$ & \multicolumn{1}{|c|}{$\begin{array}{c}\text { Angle of curvature } \\
\text { (degrees) }\end{array}$} & Average \\
\hline 6 & $16: 23$ & $19 \cdot 5$ \\
\hline 7 & $10: 14: 20: 24: 27: 29$ & 21 \\
\hline 8 & $11: 18$ & $14 \cdot 5$ \\
\hline 9 & 18 & 18 \\
\hline 10 & No cases & - \\
\hline
\end{tabular}


TABLE VI

The Results in Fifty-Nine CaSes of Thoracoplasty Without Apicolysis aNd With the Scapula NOT EMBEDDED

\begin{tabular}{|c|l|c|}
\hline $\begin{array}{c}\text { Number } \\
\text { of ribs }\end{array}$ & \multicolumn{1}{|c|}{$\begin{array}{c}\text { Angle of curvature } \\
\text { (degrees) }\end{array}$} & Average \\
\hline 3 & $6: 11$ & $8 \cdot 5$ \\
4 & $0: 4: 11$ & 5 \\
5 & From 3:6 to $16: 17$ (12 cases) & 10 \\
6 & $6: 18: 18: 21$ & 16 \\
7 & From 0:4 to $25: 61$ (16 cases) & 18 \\
8 & From 10:17 to $25: 31$ (9 cases) & 21 \\
9 & From 9:10 to $25: 27$ (8 cases) & 17 \\
10 & $18: 18: 21: 22: 30$ & 22 \\
\hline
\end{tabular}

TABLE VII

The Results in Seventy-four Cases of Thoracoplasty Without Apicolysis but With the SCapUla EMbedded

\begin{tabular}{|c|l|c|}
\hline $\begin{array}{c}\text { Number } \\
\text { of ribs }\end{array}$ & \multicolumn{1}{|c|}{$\begin{array}{c}\text { Angle of curvature } \\
\text { (degrees) }\end{array}$} & Average \\
\hline 5 & $10: 13$ & $11 \cdot 5$ \\
\hline 6 & From 7:10 to $26: 27$ (14 cases) & 19 \\
7 & From 6:7 to $24: 25$ (29 cases) & 14 \\
8 & From 4:4 to $27: 28(18$ cases) & 14 \\
9 & $10: 13: 17: 17: 22$ & 16 \\
10 & $9: 9: 17: 18: 23: 40$ & 19 \\
\hline
\end{tabular}

TABLE VIII

The Results in Eleven Cases of Thoracoplasty With PNeUmonectomy

\begin{tabular}{|c|c|c|}
\hline $\begin{array}{c}\text { Number } \\
\text { of ribs }\end{array}$ & $\begin{array}{c}\text { Angle of curvature } \\
\text { (degrees) }\end{array}$ & Average \\
\hline 4 & 29 & 29 \\
\hline 5 & $11: 12: 18$ & 14 \\
\hline 6 & $10: 18$ & 14 \\
\hline 7 & $9: 20: 23: 29$ & 20 \\
\hline 8 & 21 & 21 \\
\hline
\end{tabular}

vol. 54 B, No. 3, AUgust 1972 


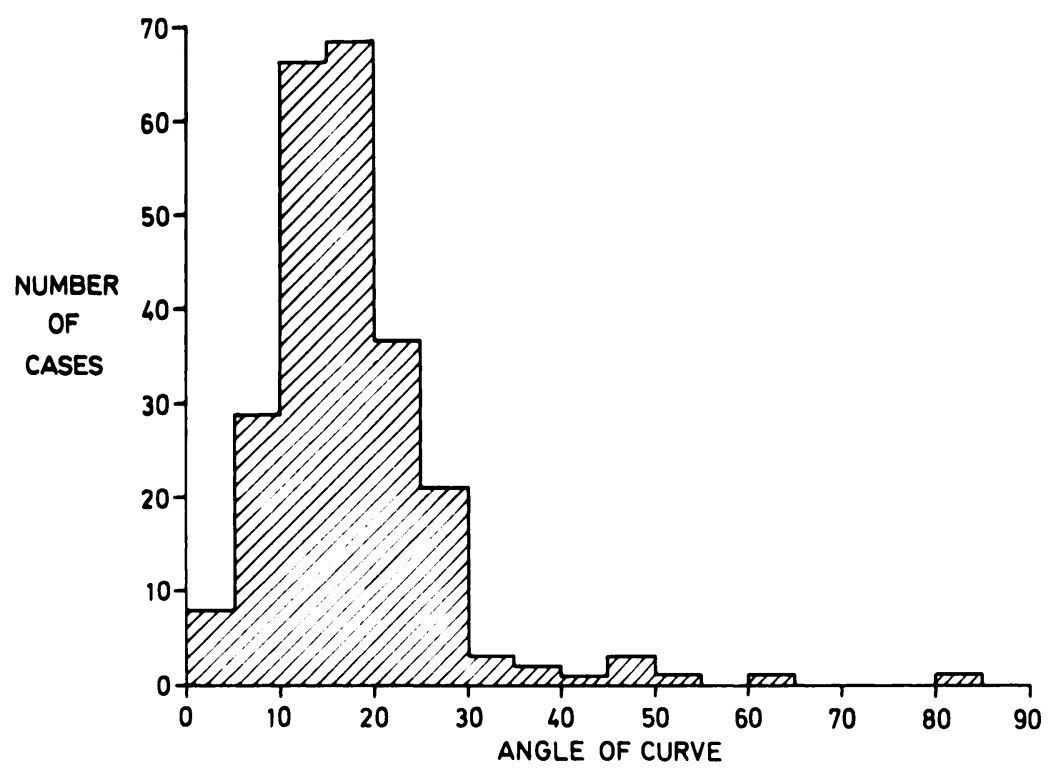

FIG. 2

The distribution of the results in the series of 243 patients.

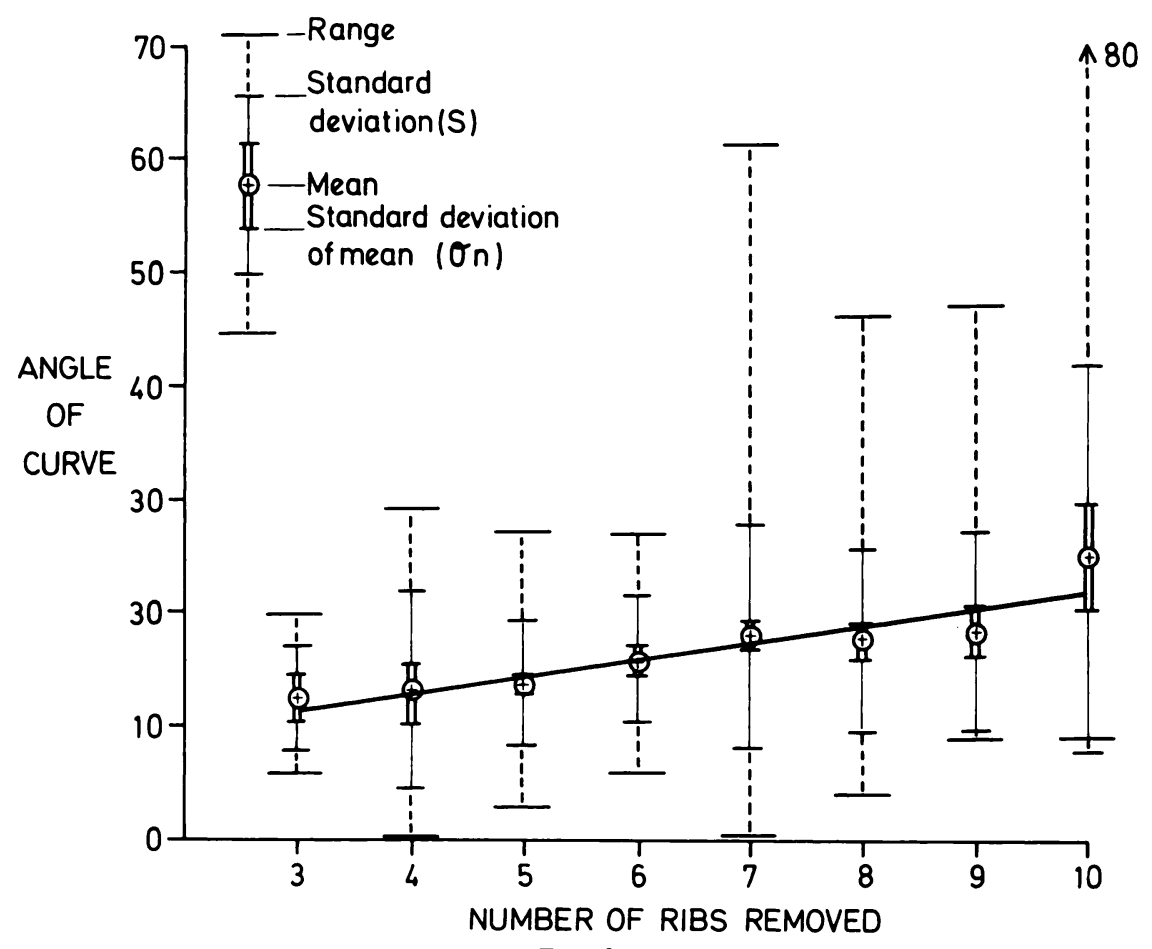

FIG. 3

Statistical analysis of all cases in the series. 


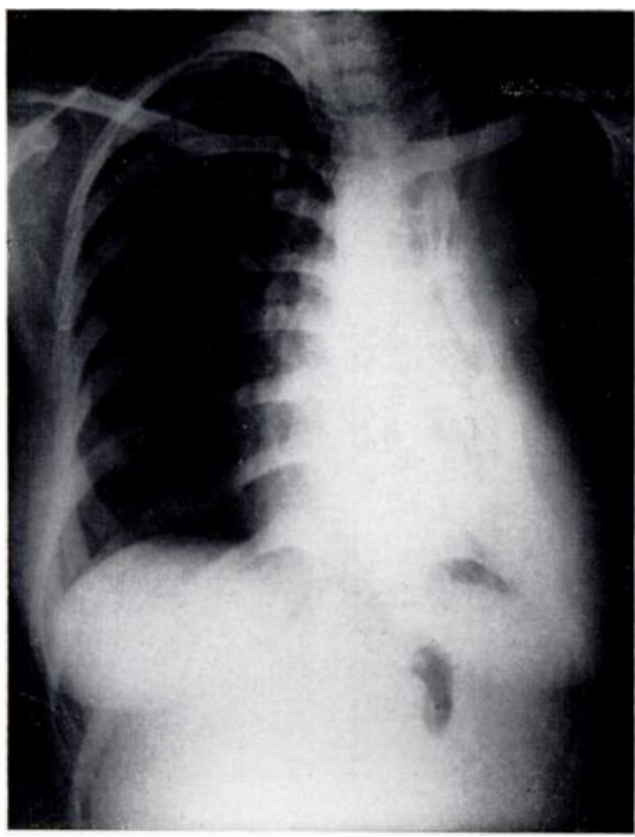

Fig. 4

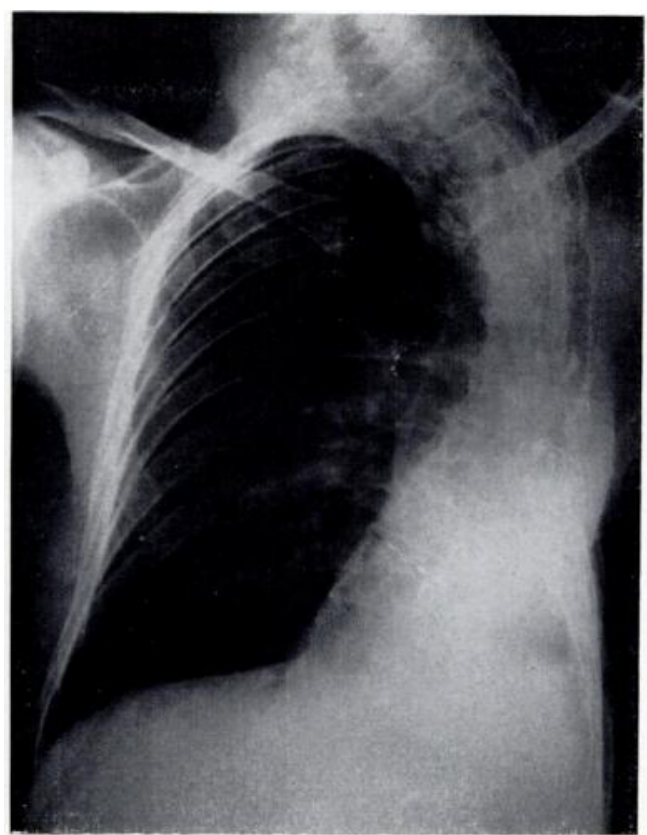

Fig. 5

Figure 4-A case of thoracoplasty in which ten ribs were excised on the left side. The result was a curve measuring 9 degrees, concave to the right. Figure 5-Another case of ten-rib thoracoplasty on the left side in which the result was a curve of 80 degrees, concave to the right. Note the poor rib fusion.

analysed separately according to the type of operation performed. The results are shown separately in Figures 6 to 11 and together in Figure 12 so that they may be compared. It is apparent that two particular groups stand out, namely, those cases in which transverse processes were removed and those in which an apicolysis was performed with embedding of the scapula. To substantiate this impression, a CHI-squared test was performed upon the values of the regression lines. The result was a series of values of CHI-squared, each corresponding to a number of ribs removed. These results are represented in Figure 13, reference to which reveals an interesting relationship. It can be seen that at the extremes of rib removal-that is, when either three or ten ribs were removed-the results in the various groups differed significantly. However, when six, seven or eight ribs were removed, the results differed only slightly. The groups of results which differed significantly from the remainder were those produced by the two operations mentioned above. The degrees of scoliosis produced by the remaining types of operation did not differ significantly (Fig. 14). One may conclude, therefore, that removal of transverse processes significantly increases the degree of scoliosis produced by thoracoplasty and that apicolysis with embedding of the scapula significantly decreases it.

It was propounded by Morris, Lucas and Bresler in 1961 that the thoracic cage and contained lungs form paired "pneumatic cylinders" which support the thoracic spine, and it was suggested by Stauffer and Mankin in 1966 that the imbalance between these pneumatic cylinders, caused by unilateral thoracoplasty, might be a contributory cause of thoracoplasty scoliosis. In an attempt to gain more evidence on this particular aspect of the problem, a comparison was made between those cases in which air refills were or were not performed after operation. In the group of cases treated by thoracoplasty with apicolysis twenty-seven patients had refills and thirty-six had none. No significant difference could be found between the two groups (Fig. 15). Of relevance to this point is the fact that no significant difference could be found between the degrees of scoliosis produced by thoracoplasty with and without

VOL. 54 B, NO. 3, AUGUST 1972 


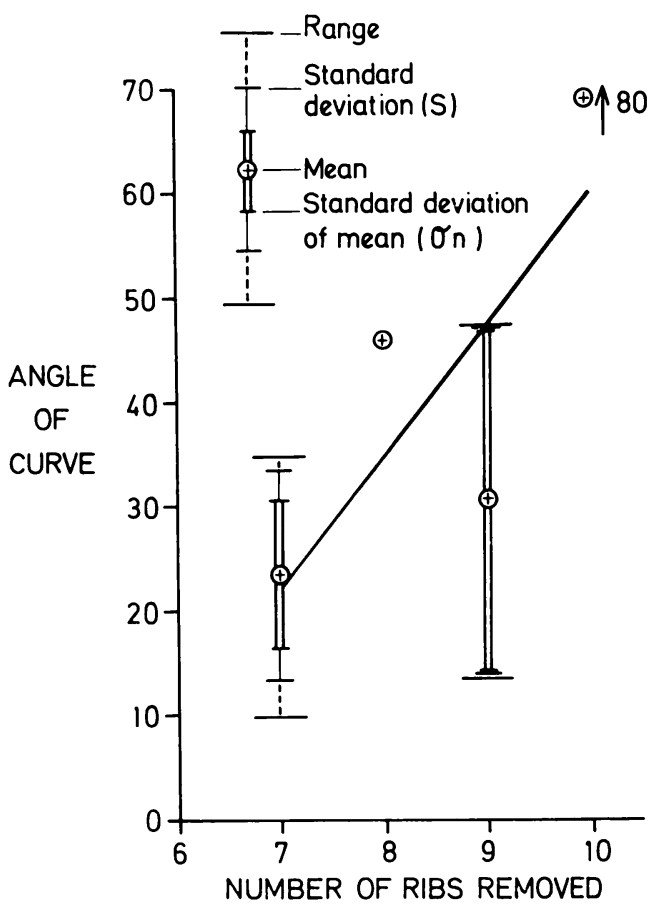

FIG. 6

Statistical analysis of cases of thoracoplasty with removal of transverse processes. pneumonectomy (Figs. 12 and 14). Thus, in this series, there was no evidence to support the theory of imbalanced "pneumatic cylinders" causing thoracoplasty scoliosis.

Age of the patient-There was found to be a considerable variation in age at the time of thoracoplasty-namely from seventeen to fifty-nine years, with a mean of thirty-one. However, investigation failed to reveal any correlation between the age at operation and the angle of the curve produced.

Progression of the curve-In an effort to trace the progress of thoracoplasty scoliosis, an attempt was made to obtain radiographs of some of the patients taken many years after operation. Unfortunately, because of the passage of time, it was only possible to obtain forty-four. Because of destruction of old films in some cases and death of the patient in others, the duration of this follow-up was not uniform, ranging from ten to twenty-two years with an average of fourteen. However, it was possible to estimate the average change of angle at certain times after operation, and this was done for each group of number of ribs removed.

The angles found at different stages after operation were expressed as a percentage of the final angle after ten to twenty-two years, and the results are shown in Table IX. It can be seen that the average change taking place during the first week after operation is nearly 50 per cent of the total, that the average change during the first six months after operation is 64 per

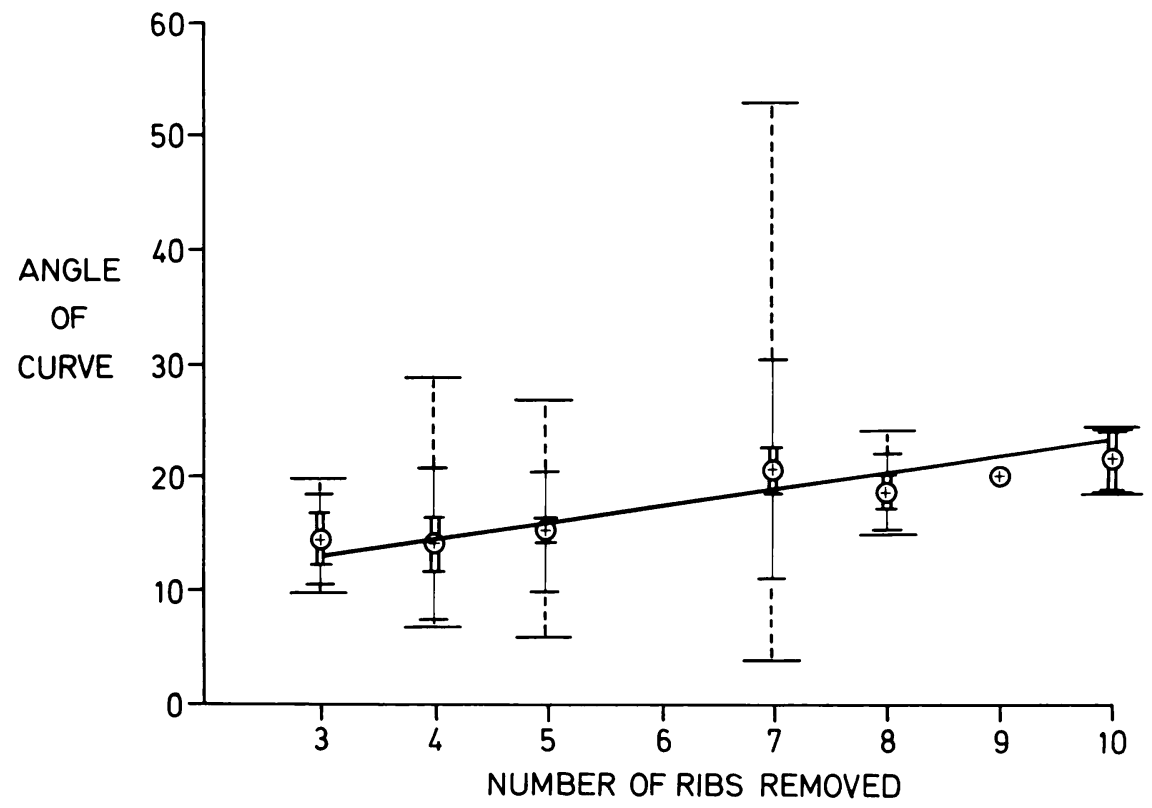

FIG. 7

Statistical analysis of cases of thoracoplasty with apicolysis but scapula not embedded. 
cent, and that a further 36 per cent occurs between six months and ten to twenty-two years later. The rate of progression of deformity did not vary with the number of ribs removed (Fig. 16).

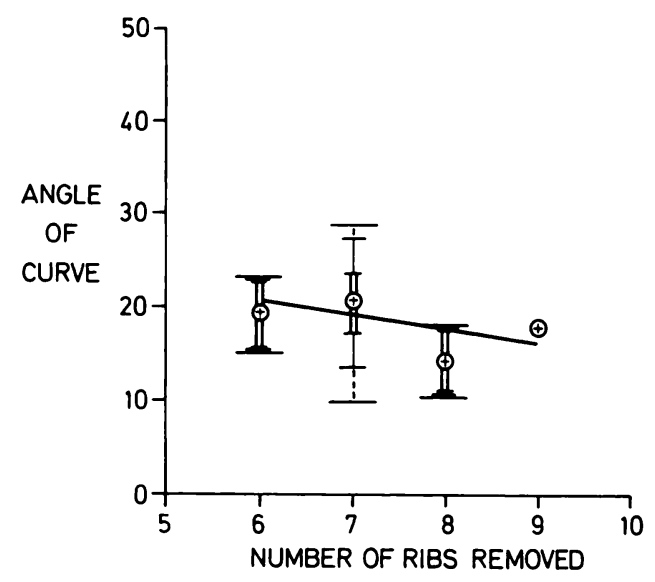

FIG. 8

Statistical analysis of cases of thoracoplasty with apicolysis and with scapula embedded.

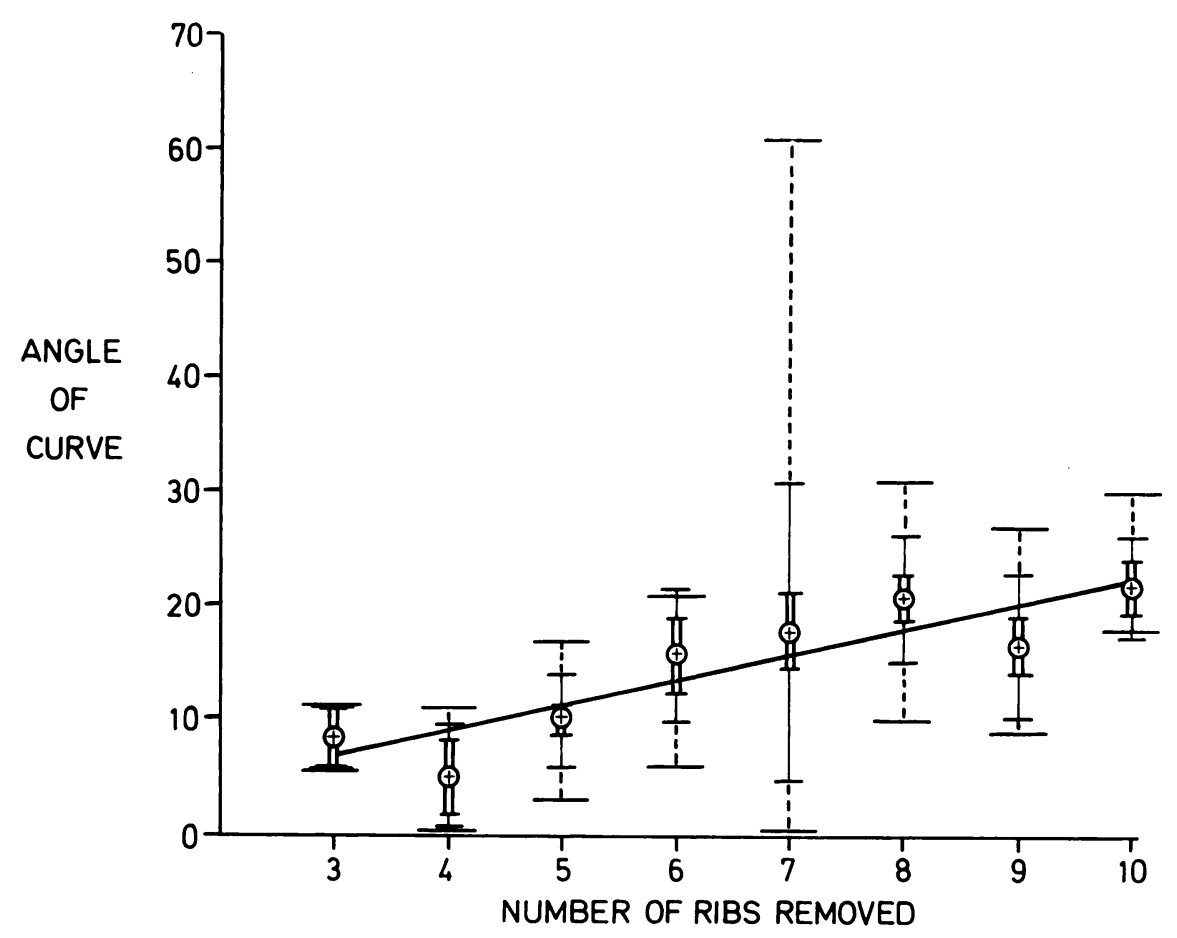

Fig. 9

Statistical analysis of cases of thoracoplasty without apicolysis and with scapula not embedded.

Rotation of vertebrae--The rotation of the apical vertebra was assessed by the method previously described; the results are shown in Table $\mathrm{X}$ and in Figure 17. It can be seen that as the number of ribs removed increases, so the incidence and the amount of vertebral rotation increase.

VOL. 54 B, NO. 3, AUGUST 1972 
Level of the apex-As expected, the level of the apical vertebra bore a highly significant relationship to the number of ribs removed, although there was some variation in the results (Fig. 18).

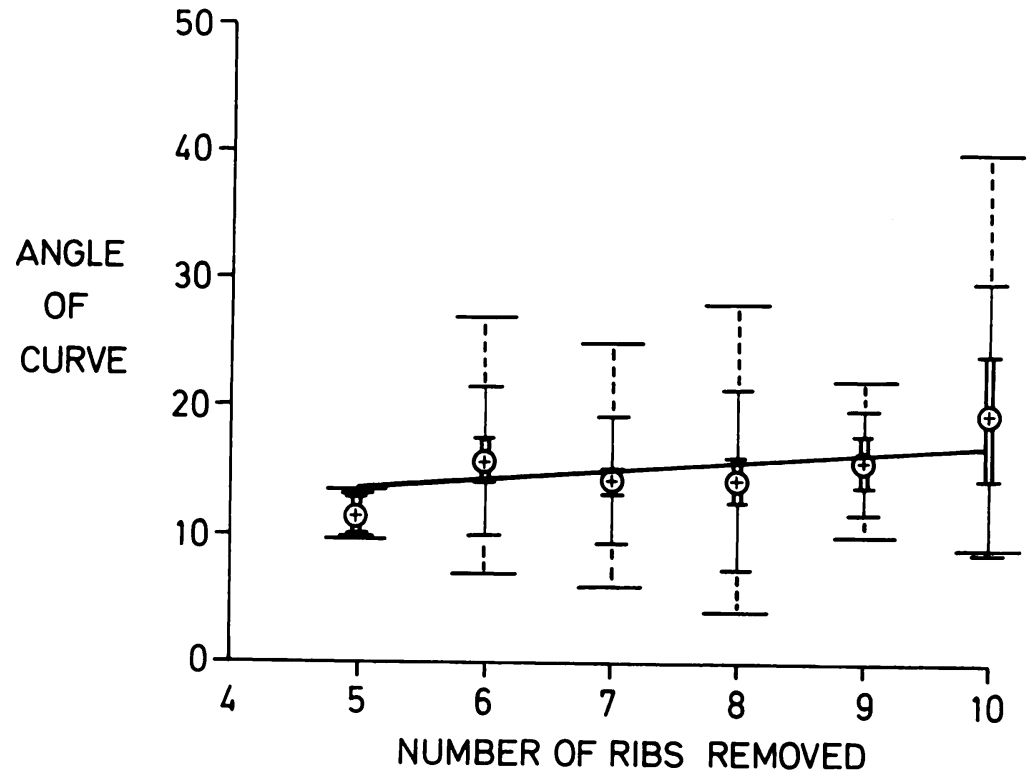

Fig. 10

Statistical analysis of cases of thoracoplasty without apicolysis but with scapula embedded.

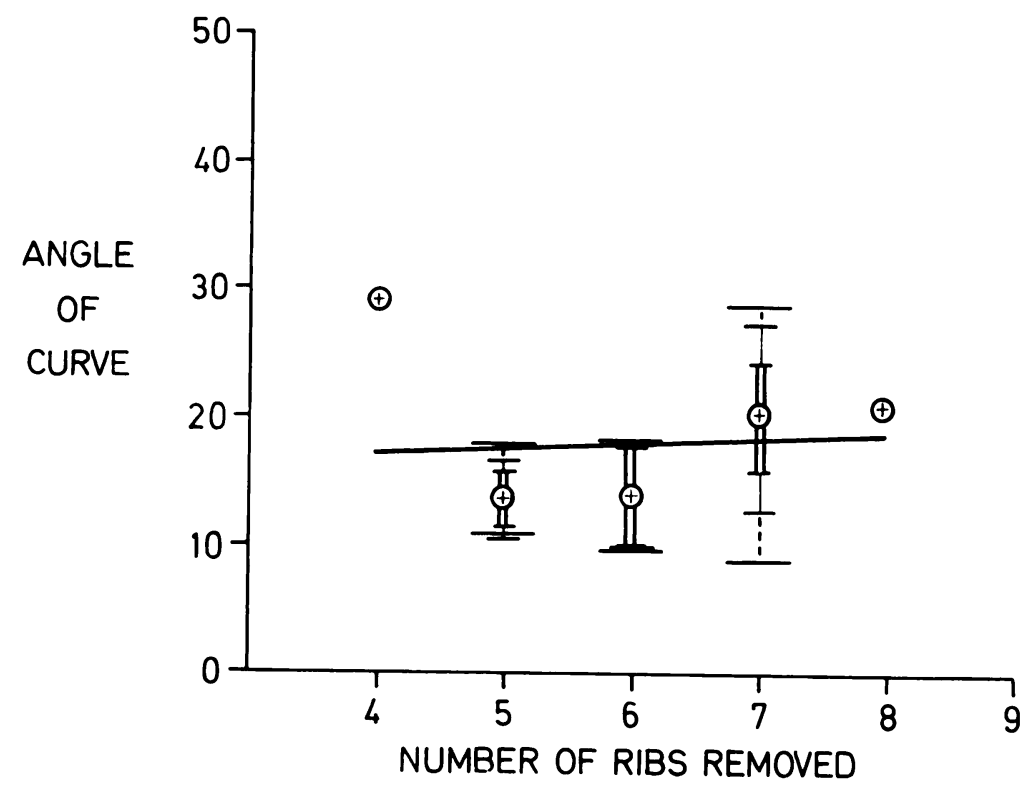

Fig. 11

Statistical analysis of cases of thoracoplasty with pneumonectomy.

DISCUSSION

It can be seen from the results that, although there is a strong correlation between the number of ribs removed at thoracoplasty and the degree of scoliosis, as found by previous authors (Stauffer and Mankin 1966), certain types of operation produce a significantly different 


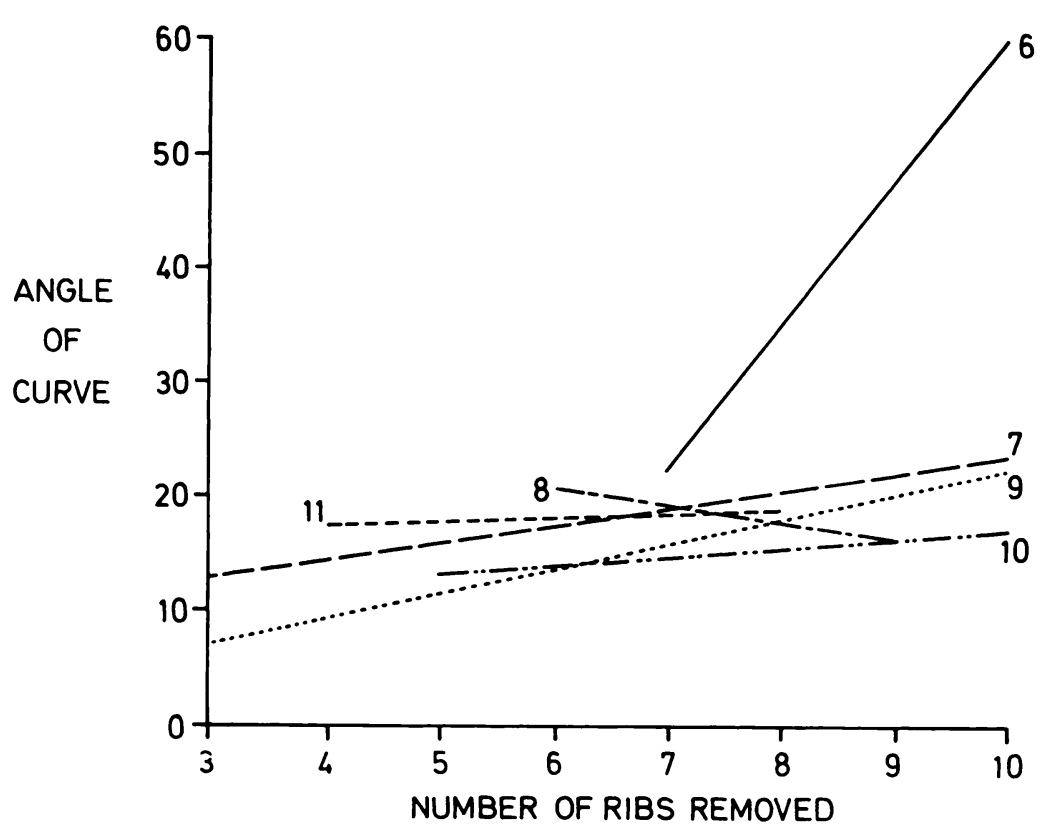

Fig. 12

The regression lines in Figures 6 to 11 shown for comparison. Line 6 from Figure 6, line 7 from Figure 7, etc.

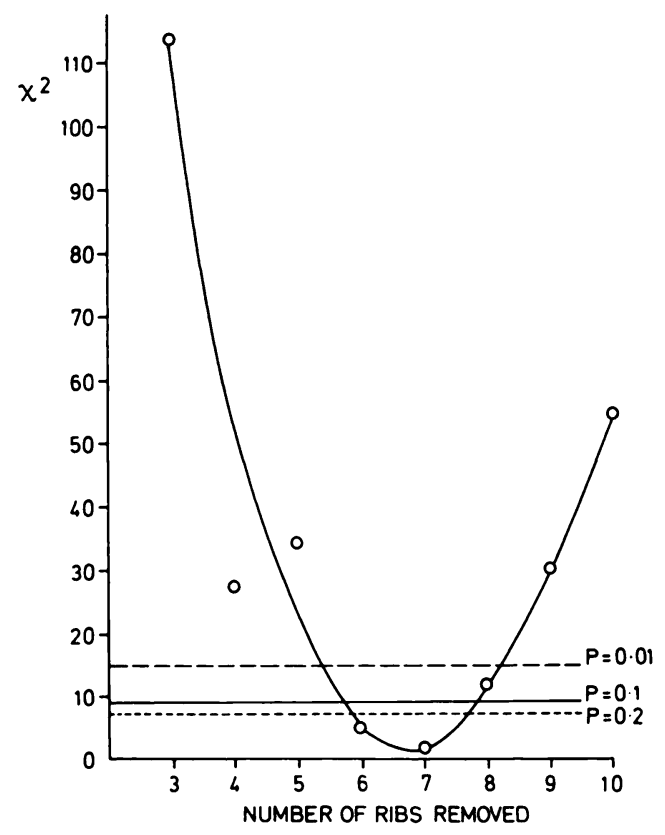

FiG. 13

Each "point" represents a CHI squared test performed on the values of the regression lines in Figures 6 to 11

for each given number of ribs removed at thoracoplasty.

Values of $\chi^{2}$ for $P=0.01,0.1$ and 0.2 are also shown.

vol. 54 B, NO. 3, AUGUST 1972 


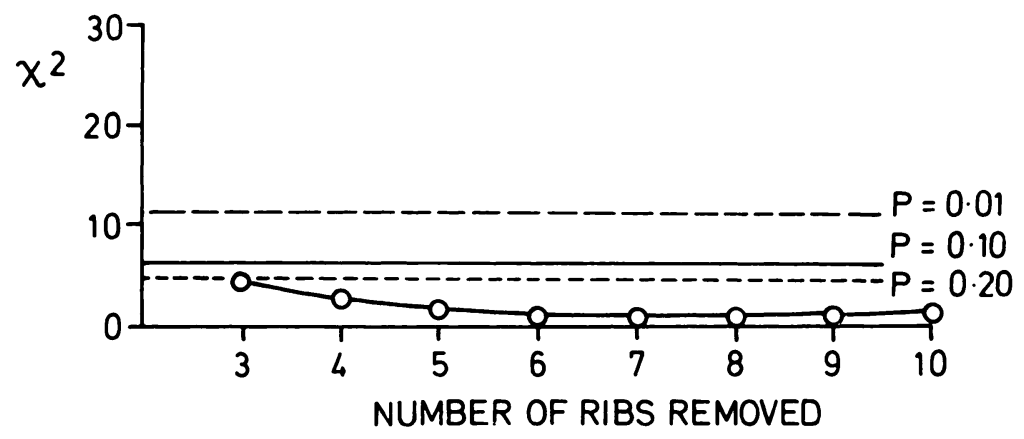

FIG. 14

Same as Figure 13 but with results of "Thoracoplasty with removal of transverse processes" and "Thoracoplasty with apicolysis and embedding of scapula "excluded.

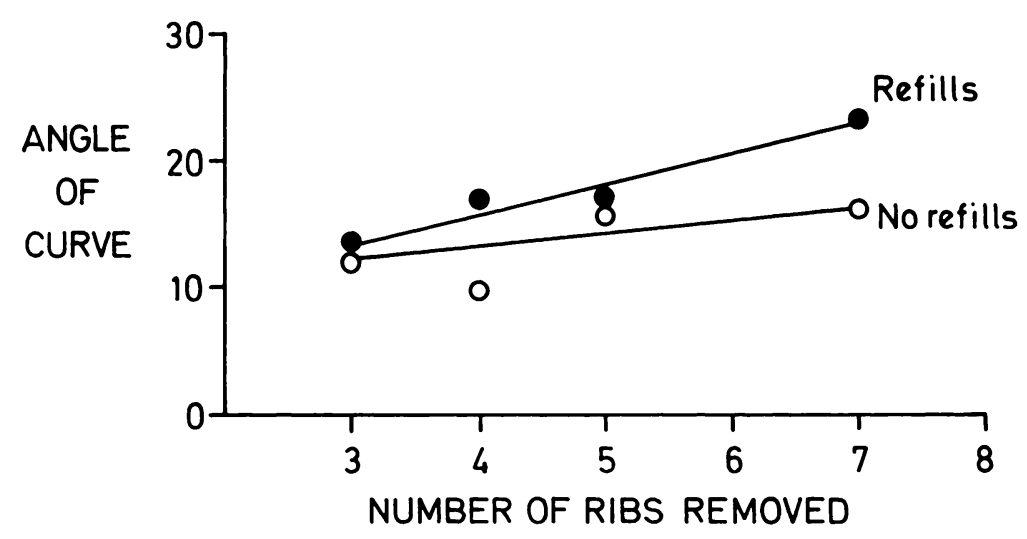

Fig. 15

A comparison of the results of cases with and without post-operative "Semb" space air refills.

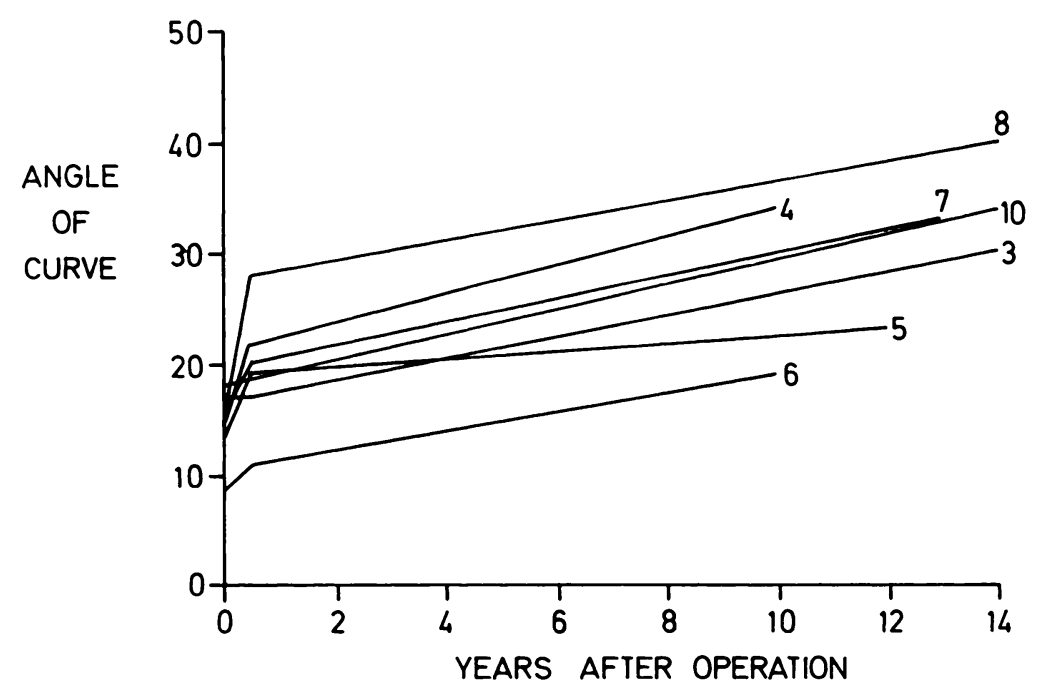

FIG. 16

Progression of curve in each group of cases with a specific number of ribs removed. There is little difference between the groups with regard to the ultimate rate of progress. 
degree of scoliosis. However, scoliosis nearly always occurs after thoracoplasty (in over 99 per cent of cases) and is always convex towards the side of operation.

In the present study it was found that removal of transverse processes along with the head, neck and tubercle of the ribs was followed by a greater angle of scoliosis. The reason for this is not certain, but the removal of transverse processes must surely involve more trauma to

TABLE IX

To Show the Progression of Scoliosis after Thoracoplasty Expressed as Average Percentages over Three Periods after Operation

\begin{tabular}{|c|c|c|c|c|}
\hline $\begin{array}{l}\text { Number of } \\
\text { ribs resected }\end{array}$ & $\begin{array}{c}\text { Percentage of } \\
\text { curvature } \\
\text { during first week }\end{array}$ & $\begin{array}{l}\text { Percentage from } \\
\text { first week to } \\
\text { six months }\end{array}$ & $\begin{array}{l}\text { Percentage from } \\
\text { six months } \\
\text { onwards }\end{array}$ & $\begin{array}{c}\text { Longest period } \\
\text { of follow-up } \\
\text { (years) }\end{array}$ \\
\hline 3 & 57 & - & 43 & 14 \\
\hline 4 & 44 & 21 & 35 & 10 \\
\hline 5 & 61 & 22 & 17 & 12 \\
\hline 6 & 50 & 11 & 39 & 10 \\
\hline 7 & 48 & 12 & 40 & 13 \\
\hline 8 & 32 & 28 & 40 & 22 \\
\hline 9 & \multicolumn{3}{|c|}{ No cases } & \\
\hline 10 & 43 & \multicolumn{2}{|c|}{57} & 21 \\
\hline $\begin{array}{l}\text { Averages, excluding } \\
\text { 10-rib thoracoplasty }\end{array}$ & 49 & $15 \cdot 5$ & 36 & \\
\hline
\end{tabular}

TABLE X

Percentage of Cases of 0,1 and 2 Degrees of Rotation in Each Group

\begin{tabular}{|c|c|c|c|}
\hline $\begin{array}{c}\text { Ribs } \\
\text { resected }\end{array}$ & 0 & 1 & 2 \\
\hline 3 & 40 & 60 & - \\
\hline 4 & 17 & 83 & - \\
\hline 5 & 45 & 55 & - \\
\hline 6 & $9 \cdot 5$ & $90 \cdot 5$ & - \\
\hline 7 & 32 & 68 & - \\
\hline 8 & $12 \cdot 5$ & $87 \cdot 5$ & - \\
\hline 9 & 8 & 84 & 8 \\
\hline 10 & 9 & 82 & 9 \\
\hline
\end{tabular}

the erector spinae muscles, hence increasing any imbalance of muscle power. The removal of transverse processes involves complete excision of the costo-transverse joint and disturbance of the costo-vertebral joint, and this could explain the greater angle of curvature. Whether this is due to purely mechanical factors or to neurological factors is not known. It could be that a balanced input from the proprioceptors of the costo-transverse and costo-vertebral joints on both sides is necessary for a stable spine. Another possible mechanism of interference with 
input to the spinal cord is damage to the intercostal nerves and posterior nerve roots (MacEwen 1968). The chance of damage to the intercostal nerves is almost certainly increased by removal of the transverse process and head, neck and tubercle of a rib. The role of regenerated rib remnants will be discussed later, but it is relevant here to mention the possibility that a more complete removal of the rib along with the transverse process may result in a more tenuous connection between a regenerated rib remnant and the spine.

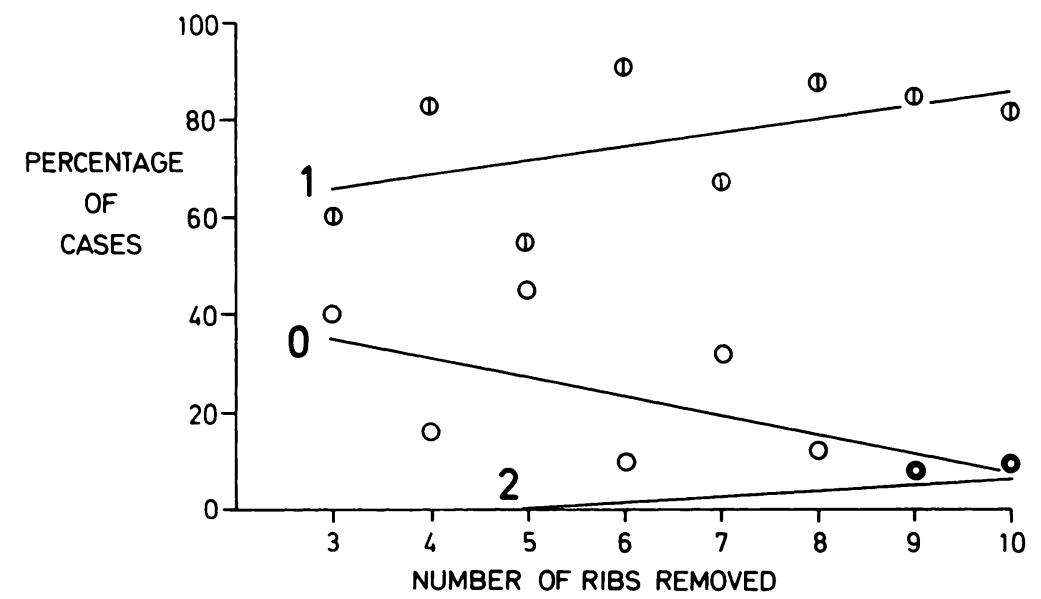

FIG. 17

To show the incidence of 0,1 and 2 degrees of rotation compared with the number of ribs removed.

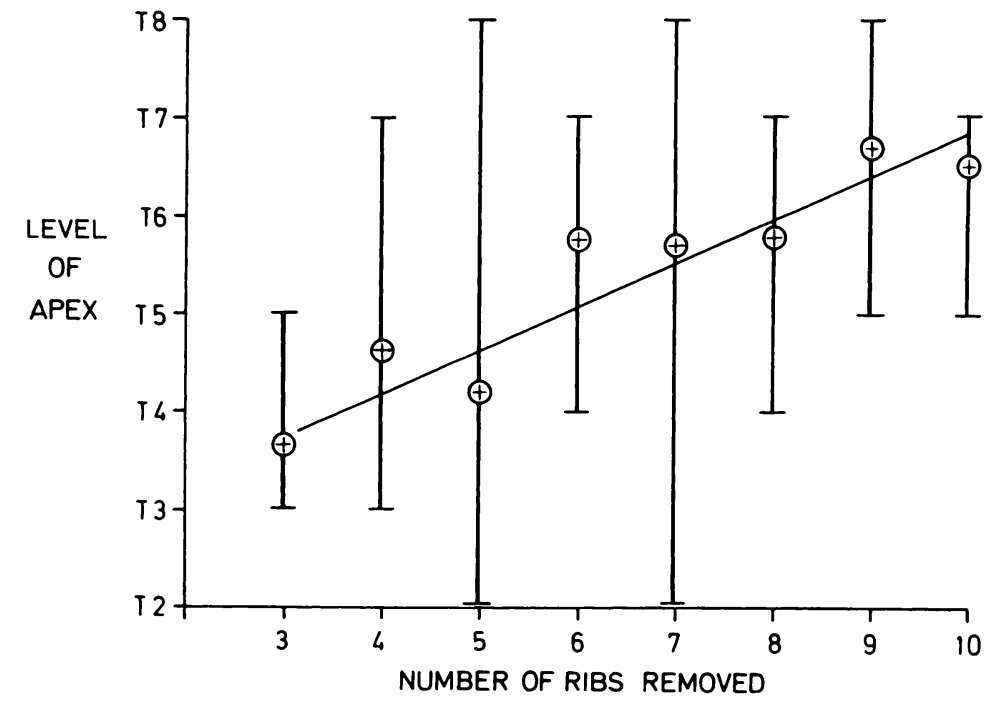

Fig. 18

To show the relationship between the level of the apical vertebra and the number of ribs removed. Mean values, range of values and the regression line are shown.

To be compared with the foregoing is the fact that thoracoplasty combined with apicolysis and embedding of the scapula produces less curvature than thoracoplasty alone. A possible explanation is found in the amount of "tethering" produced on the side of operation; in such combined procedures the amount of scarring could well be much greater. This fact, together with the more rigid fixation of the scapula, could account for the lesser degree of scoliosis produced. 
The evidence found in the present study suggests that the different degrees of scoliosis produced by various techniques of thoracoplasty are most evident if either few (three) or many (ten) ribs are removed (Fig. 13). Possibly this is because at these "extremes" any minor differences between the various operations exert a more critical effect on subsequent spinal instability. It is also possible that this effect is an artefact produced by the fact that there are fewer results to compare in these ranges of rib removal, so that any differences become more apparent.

The progression of thoracoplasty scoliosis appears to be rapid initially, about half of the final angle developing within the first week. However, slow progression does occur for many years after operation (Fig. 16). This early onset of deformity suggests considerable muscle imbalance. It is of interest to note that, although it was impossible in this series to quantify the effect of post-operative exercises and physiotherapy on the incidence of spinal deformity, the late $\mathrm{Mr} \mathrm{H}$. Morriston-Davies believed that he could prevent spinal deformity after thoracoplasty by physiotherapeutic measures. The slow progression over many years suggests the continuance of deforming forces, possibly unequal muscle action, which inexorably overcome any factor restricting the development of spinal curvature. Such restricting factors include post-

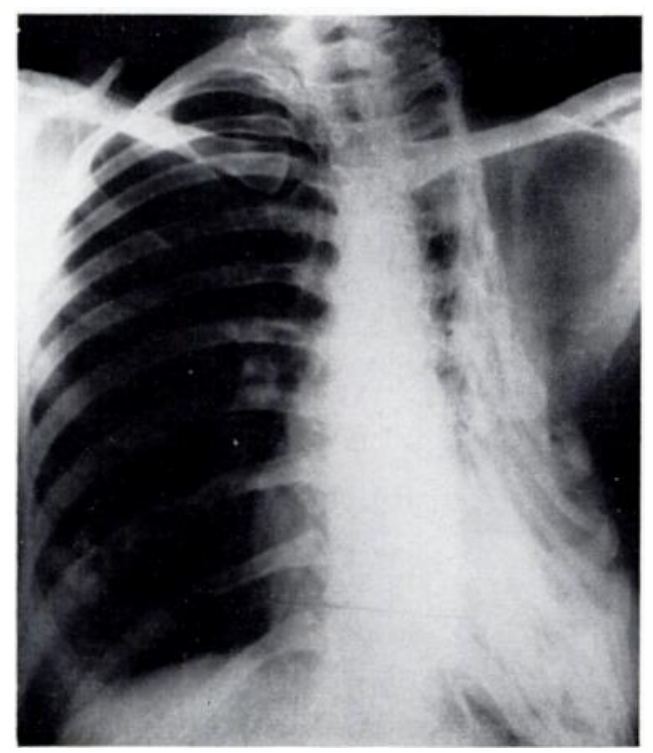

FiG. 19

A case in which there was good rib fusion, resulting in a mild curve despite an extensive thoracoplasty. operative fibrosis and the fusion of rib remnants. It is, for instance, noticeable that in some cases there appears to be good bony fusion between the regenerated rib remnants (Fig. 19) and in other cases poor rib fusion (Fig. 5).

It is also interesting in this context to note the results of the bilateral thoracoplasty performed. Pre-operatively, there was no scoliosis, but some seven months after a left-sided seven-rib thoracoplasty with embedding of the scapula, there was a scoliosis of 15 degrees convex to the left. However, a right-sided four-rib thoracoplasty was then performed. This failed to alter the angle of the scoliosis over the next four months; the degree of vertebral rotation was also unchanged. Presumably the deforming forces which could have acted after the second thoracoplasty were destroyed or markedly reduced during the first procedure.

In this series there was no evidence to suggest that the age of the patient at the time of thoracoplasty had any influence upon the final degree of deformity. This was presumably because in all cases spinal maturity had already been reached. It is of interest to note, however, that the spines of patients aged seventeen and fifty-nine years are capable of deformation to the same extent.

\section{SUMMARY}

1. The results of 243 thoracoplasty operations are discussed. It was found that scoliosis developed in over 99 per cent of cases and that the curve was convex towards the side of operation. The angle of curvature correlated closely with the number of ribs removed.

2. If the head, neck and tubercle of the rib and the transverse process of the corresponding vertebra were all removed the degree of scoliosis was increased, whereas if a thoracoplasty was performed with apicolysis and embedding of the scapula the spinal deformity was less. Possible explanations for these phenomena are discussed.

3. No evidence was found to support the theory of causation by imbalance between the paired "pneumatic cylinders" (lungs and thoracic cage) supporting the thoracic spine.

VOL. 54 B, NO. 3, AUGUST 1972 
4. The scoliosis was found to progress for many years; some factors influencing this course are discussed.

5. No correlation was found between the age of the patient at the time of thoracoplasty and the degree of subsequent scoliosis, but severe spinal deformity can arise even in older adults.

My thanks are due to Professor R. Roaf for assistance with this paper, and to the staff of the Orthopaedic Department, University of Liverpool. Thanks are also due to Dr R. W. Biagi, superintendent of Llangwyfan

Hospital, Denbighshire, and to Dr J. T. Foody, Barrowmore Hospital, near Chester, for their help in tracing patients, and to $\mathrm{Mr} \mathrm{L}$. Temple and $\mathrm{Mr} \mathrm{T}$. Howell-Hughes for permission to include many of their operative cases in this report.

\section{REFERENCES}

BISGARD, J. D. (1934): Thoracogenic Scoliosis. Influence of Thoracic Disease and Thoracic Operations on the Spine. Archives of Surgery, 29, 417.

Bisgard, J. D. (1935): Experimental Thoracogenic Scoliosis. Journal of Thoracic Surgery, 4, 435.

BisHOP, O. N. (1969): Statistics for Biology, p. 30. London: Longmans Ltd.

Совв, J. R. (1948): Outline for the Study of Scoliosis. American Academy of Orthopaedic Surgeons, Instructional Course Lectures, 5, 261.

Hutter and Volkmann, (1869): Handbuch der allgemeinen und speziellen Chirurgie. Band II, 1, 694. Edited by Pitha and Bilroth.

LANGENSK IöLD, A. (1968): Experimental Scoliosis. In Proceedings of a Second Symposium on Scoliosis: Causation, p. 21. Edited by P. A. Zorab. Edinburgh and London: E. \& S. Livingstone Ltd.

Langenskiöld, A., and Michelsson, J.-E. (1961): Experimental Progressive Scoliosis in the Rabbit. Journal of Bone and Joint Surgery, 43-B, 116.

Langenskiöld, A., and Michelsson, J.-E. (1962): The Pathogenesis of Experimental Progressive Scoliosis. Acta orthopaedica Scandinavica, Supplementum 59.

MaCewen, D. G. (1968): Experimental Scoliosis. In Proceedings of a Second Symposium on Scoliosis: Causation, p. 18. Edited by P. A. Zorab. Edinburgh and London: E. \& S. Livingstone Ltd.

MANNING, C. W. (1968): Experimental Scoliosis. In Proceedings of a Second Symposium on Scoliosis: Causation, p. 11. Edited by P. A. Zorab. Edinburgh and London: E. \& S. Livingstone Ltd.

Michelsson, J.-E. (1965): The Development of Spinal Deformity in Experimental Scoliosis. Acta orthopaedica Scandinavica, Supplementum 81.

Morris, J. M., Lucas, D. B., and Bresler, B. (1961): Role of the Trunk in Stability of the Spine. Journal of Bone and Joint Surgery, 43-A, 327.

NASH, C. L., Jun., and MoE, J. H. (1969): A Study of Vertebral Rotation. Journal of Bone and Joint Surgery, 51-A, 223.

Stauffer, E. S., and Mankin, H. J. (1966): Scoliosis after Thoracoplasty. Journal of Bone and Joint Surgery, 48-A, 339. 